\title{
Developing a guideline for clinical trial protocol content: Delphi consensus survey
}

Jennifer Marie Tetzlaff ${ }^{*}$, David Moher ${ }^{1,2}$ and An-Wen Chan ${ }^{3}$

\begin{abstract}
Background: Recent evidence has highlighted deficiencies in clinical trial protocols, having implications for many groups. Existing guidelines for randomized clinical trial (RCT) protocol content vary substantially and most do not describe systematic methodology for their development. As one of three prespecified steps for the systematic development of a guideline for trial protocol content, the objective of this study was to conduct a three-round Delphi consensus survey to develop and refine minimum content for RCT protocols.

Methods: Panellists were identified using a multistep iterative approach, met prespecified minimum criteria and represented key stakeholders who develop or use clinical trial protocols. They were asked to rate concepts for importance in a minimum set of items for RCT protocols. The main outcome measures were degree of importance (scale of 1 to 10; higher scores indicating higher importance) and level of consensus for items. Results were presented as medians, interquartile ranges, counts and percentages.

Results: Ninety-six expert panellists participated in the Delphi consensus survey including trial investigators, methodologists, research ethics board members, funders, industry, regulators and journal editors. Response rates were between 88 and $93 \%$ per round. Overall, panellists rated 63 of 88 concepts of high importance (of which 50 had a $25^{\text {th }}$ percentile rating of 8 or greater), 13 of moderate importance (median 6 or 7 ) and 12 of low importance (median less than or equal to 5) for minimum trial protocol content. General and item-specific comments and subgroup results provided valuable insight for further discussions.

Conclusions: This Delphi process achieved consensus from a large panel of experts from diverse stakeholder groups on essential content for RCT protocols. It also highlights areas of divergence. These results, complemented by other empirical research and consensus meetings, are helping guide the development of a guideline for protocol content.

Keywords: Randomized controlled trials, Delphi consensus survey, SPIRIT Initiative, Protocols, Clinical trials, Reporting guideline
\end{abstract}

\section{Background}

The protocol of a randomized clinical trial (RCT) serves many purposes. Protocols provide investigators with a document to guide trial conduct; trial participants with a detailed description of trial methodology; research ethics committees/institutional review boards (REC/IRBs) with a foreknowledge of predefined safeguards to protect participants' interests and safety; research funders with a means of assessing proposed methods; and systematic

\footnotetext{
*Correspondence: jtetzlaff@ohri.ca

'Ottawa Methods Centre, Clinical Epidemiology Program, Ottawa Hospital Research Institute, 501 Smyth Road, Ottawa, ON K1H 8L6, Canada Full list of author information is available at the end of the article
}

reviewers and others with a description of prespecified methods to evaluate potential biases [1-8]. To fulfill these purposes, protocols must be clear, detailed and transparent.

Unfortunately, many protocols do not adequately describe important methodological details such as allocation concealment (59\%) [9], primary outcomes (25\%) [1], power calculations (27\%) [3] and sponsor and investigators' roles in aspects of trial conduct [10] - all of which have been associated with exaggerated effect sizes and potential bias in trials. The lack of transparency and incomplete description of methods makes critical assessment of trials difficult.

\section{Biomed Central}

(c) 2012 Tetzlaff et al.; licensee BioMed Central Ltd. This is an Open Access article distributed under the terms of the Creative Commons Attribution License (http://creativecommons.org/licenses/by/2.0), which permits unrestricted use, distribution, and reproduction in any medium, provided the original work is properly cited. 
Reporting guidelines have been developed to help improve deficiencies in research reports [11-18]. A recent systematic review examined 40 guidelines for trial protocols; only $20 \%$ included any description of their methodological development process. Of those reporting consensus methods, none described formal processes for achieving consensus among stakeholders (for example Nominal consensus technique, Delphi consensus) and none described a systematic consideration of empirical evidence for guideline development [19]. Additionally, recommendations differed considerably across guidelines and many did not include concepts supported by empirical evidence. These inconsistencies and deficiencies have implications for those preparing, using, and reviewing clinical trial protocols.

An international group of researchers launched the SPIRIT (Standard Protocol Items: Recommendations for Interventional Trials) Initiative in 2007, with the primary aim of increasing the transparency and completeness of trial protocols. The main product of this initiative is a checklist of key items to address in protocols of clinical trials. This guideline is being developed with systematic and transparent methodology.

In line with current recommendations [20], three complementary methods were specified a priori to develop the SPIRIT checklist: 1) a Delphi consensus survey involving key expert stakeholders in the development and use of clinical trial protocols; 2) a systematic review of empirical evidence supporting the importance of specific checklist items; and 3) face-to-face consensus meetings to develop and finalize the SPIRIT Statement and its associated explanatory document. This paper describes in detail the first component of this research.

\section{Methods}

The objective of this study was to develop and refine minimum content for RCT protocols by expert consensus. We conducted a three-round electronic Delphi survey. Ethics approval was obtained through the Children's Hospital of Eastern Ontario.

\section{Selection of participants}

Invited expert panellists represented the main stakeholders involved in clinical trials: investigators, methodologists, statisticians and senior study coordinators from academia, pharmaceutical industry and government; REC/IRB members; members of funding and regulatory agencies; and major healthcare journal editors. Experts had to meet the following predefined criteria [21]: relevant knowledge and experience; capacity, willingness and sufficient time to participate; and ability to communicate effectively in English. Participants were selected based on expertise and, where possible, were ranked and selected according to objective criteria (trialists were required to be an author on a minimum of five English-language RCT publications over the past 10 years).

We identified potential panellists using a multistep, iterative approach [22], which included nomination/ snowballing, authors of relevant methodological research and the Institute for Scientific Information's 'Highly cited researchers in clinical medicine' [23]. This search was supplemented by specific location-based PubMed searches and targeted Internet searching to increase geographical distribution and areas of panellist expertise. Our objective was to include approximately 100 panellists (40 trialists/clinicians, 20 methodologists, 15 study coordinators, 10 ethics board heads/members, 10 funding/regulatory agency representatives and 5 healthcare journal editors) to enable detection of any divergent opinions between experts groups.

\section{Selection of preliminary items}

An initial list of 59 potential checklist items was collated based on existing protocol guidance [19] and known empirical evidence. Items were grouped under the following broad headings: a) General information; b) Introduction; c) Methods; d) Trial organization and administration; e) Ethical considerations; f) Reporting and dissemination; and g) Other. Each item included a heading and description; wording and structure were kept similar to existing guidelines, where possible.

\section{Delphi survey}

All correspondence occurred via email or facsimile. Approximately two weeks before the survey was administered (August 2007), we informed potential participants of the objectives of the SPIRIT Initiative and Delphi process, and invited them to participate. We solicited reasons for declining, where relevant. Participant anonymity and confidentiality of responses were ensured; individual responses were known only to the moderator (JT). Each survey round was conducted over five to six weeks: one week for pilot testing, three weeks for response acquisition (including two reminders prior to the round closing date) and one week for collating the results and preparing the subsequent round.

Each candidate item was rated in at least two rounds. In each round, respondents were asked to rate items on a 10point scale (or 'No judgement') for their suitability for inclusion in a minimum checklist for RCT protocols. A rating of one corresponded to 'unimportant - should be dropped as an item to consider' and ten corresponded to 'very important - must be included'. We provided panellists with a space following each item and encouraged them to add free text comments, suggest reiterations or suggest additional items they felt would be of benefit for inclusion in the SPIRIT checklist, if relevant. Round 1 also 
collected demographic information (occupation/field and place of employment) and panellists' self-rated level of expertise in participating in this process.

Round 2 of the survey contained all Round 1 items grouped categorically by median scores rounded to the nearest whole number (median $\geq 8 ; 6 \leq$ median $\geq 7$; median $\leq 5)$. No changes were made to checklist items, aside from the addition of newly nominated items from Round 1, which were drafted to include a heading and description; as before, wording and structure were kept similar to existing guidelines, where possible. For each item, panellists were provided with their previous rating, group summary ratings (medians, interquartile ranges (IQRs) and frequency distributions) and anonymized free text comments from Round 1 (Figure 1). They were asked to re-rate the items and respond to existing comments, if desired. Panellists were informed that, following Round 2, consensus would be defined by the consistency of median scores between rounds (median $\geq$ $8=$ high importance, median $\leq 5=$ low importance) and the absence of significant issues noted in text comments.

The third and final round presented results of items reaching consensus (Parts 1 and 2) and three sections requiring additional feedback. Part 3 included items introduced in Round 2 (to be rated as before: from 1 to 10). Parts 4 and 5 included items requiring a third round of feedback: those rated of moderate importance (median 6 to 7) after two rounds (Part 4; Figure 2a) and items where comments suggested that single items contained multiple concepts of differing importance (Part 5; Figure $2 \mathrm{~b}$ ). For the latter, concepts were delineated and respondents were asked to rate each subitem separately. Each item in Parts 4 and 5 had the following response options: 'Include,' Exclude' or 'Unsure'.

\section{Analysis}

Medians and IQRs were calculated for each item. Subgroup analyses were explored by respondents' occupation and self-rated expertise.

\section{Results}

\section{Delphi participants}

Invitations to participate in the Delphi survey were sent (by email) to 167 experts; we received a response from 123 experts, of which 104 (85\%) accepted the invitation. Reasons for declining ( $\mathrm{n}=19 ; 15 \%)$ were too busy/unable $(\mathrm{n}=15)$, not interested $(\mathrm{n}=1)$ or no reason provided $(\mathrm{n}=3)$. Of the panellists agreeing to participate, eight were unable to respond to either Round 1 or 2 and were not invited to participate in Round 3. Thus, ninety-six experts comprised the final panel.

Panellists met our a priori goals for profession/expertise representation (Table 1). Eighty-nine (93\%) panellists from 17 countries responded to Round 1; 86 (90\%) panellists from 17 countries responded to Round 2; and 84 (88\%) panellists from 16 countries responded to Round 3 of the survey. Seventy-seven percent responded to all three rounds, $16 \%$ to two rounds and $7 \%$ to one round of the Delphi. Most initiated surveys had 100\% completion; missing data were sparse and were clarified individually with the respondent.

\section{Delphi results}

Figure 3 presents the flow of items through the Delphi and Tables 2 and 3 present the final results for each concept. In Round 1, respondents collectively rated 56 of the original 59 items with a median of 8 or greater, three with a median of 6 or 7 (Personnel, Logistics and Budget) and none with a median of 5 or less. All items were recirculated in Round 2, where consensus was achieved for 46 (78\%) of the original 59 items; 45 items were considered to be of high importance and 1 (Budget) of low importance. The remaining items - four rated of moderate importance in Round 2 and nine where comments suggested that clarification was necessary - were recirculated for Round 3. Of the four rated of moderate importance, three were ultimately recommended for exclusion (General Approach, Personnel and Logistics). The fifteen panellist-nominated items (rated in Rounds 2 and 3; denoted by $\mathbb{S}$ in Tables 2 and 3) included seven with a

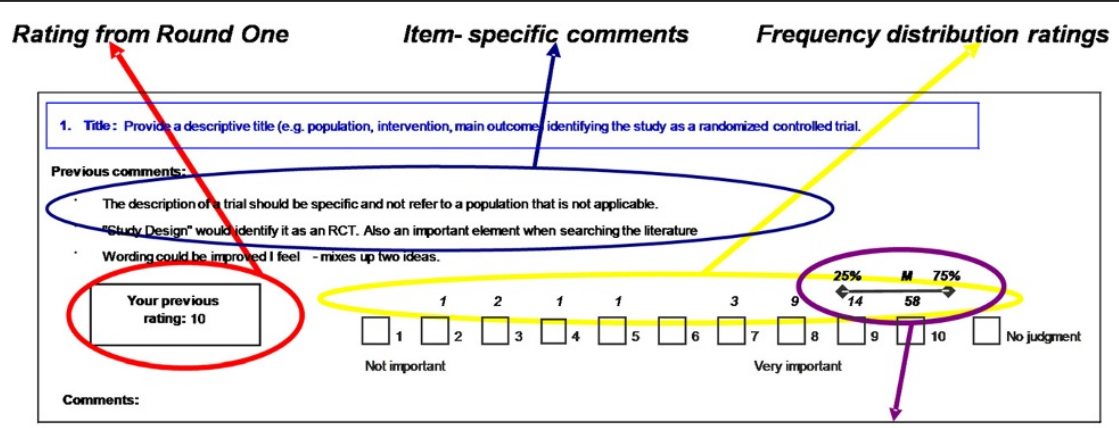

$M=$ Median $; 25 \% 75 \%$ Inter-quartile range

Figure 1 Example of questionnaire layout from Delphi Round 2. 


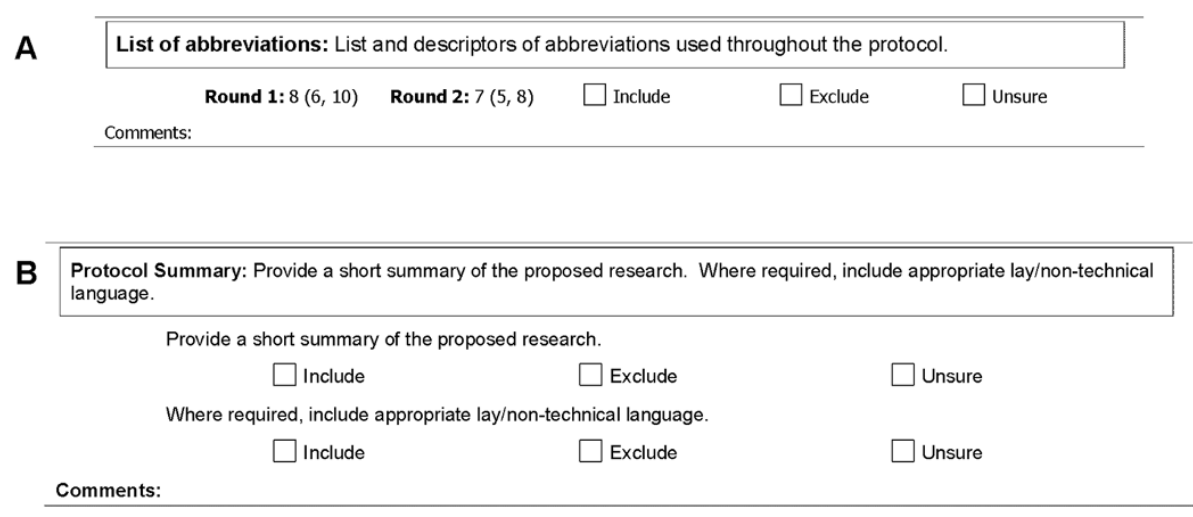

Figure 2 Example of questionnaire layout from Delphi Round 3 Parts 4 (A) and 5 (B).

median of 8 or greater, six with a median of 6 or 7; and two with a median of 5 or less (Signatures, Insurance)

Where clarification was required after Round $2(\mathrm{~N}=9$ items), panellists' ratings in Round 3 commonly demonstrated differential support for specific subcomponents

Table 1 Characteristics of Delphi survey panellists ( $N=96)$

\begin{tabular}{lc}
\hline \multicolumn{1}{c}{ Question } & N (\%) \\
\hline Profession $^{*}$ & $30(31)$ \\
\hline Clinical trialist & $28(29)$ \\
\hline Healthcare professional & $28(29)$ \\
\hline Methodologist & $16(17)$ \\
\hline Statistician & $12(13)$ \\
\hline Trial coordinator & $11(11)$ \\
\hline REC/RB member & $11(11)$ \\
\hline Journal editor & $5(5)$ \\
\hline Funding agency representative & $3(3)$ \\
\hline Regulatory agency member & $7(7)$ \\
\hline Other & $58(60)$ \\
\hline Place of employment & $30(31)$ \\
\hline University & $13(14)$ \\
\hline Hospital & $9(9)$ \\
\hline Government & $4(4)$ \\
\hline Non-profit organization & $0(0)$ \\
\hline For-profit organization & $5(5)$ \\
\hline Self-employed & $19(8)$ \\
\hline Other & $33(34)$ \\
\hline Self-perceived level of expertise for survey & $0(0)$ \\
\hline High level & \\
\hline Mid-high level & \\
\hline Mid level & \\
\hline Low-mid level & \\
\hline Som-level/no expertise & \\
\hline
\end{tabular}

"Some panellists selected more than one relevant category. REC/IRB, research ethics committee/institutional review board. (denoted by $\neq$ in Tables 2 and 3). For example, in general, where items requested specific information plus a justification, respondents strongly favoured the main concept but not the justification (for example Study locations (Include $(\mathrm{I})=87 \%$, justification: $\mathrm{I}=46 \%$ ) and Eligibility criteria $(I=99 \%$, justification: $I=66 \%)$ ). The four components of the item Monetary and material support also received differing levels of support (source of support: $I=95 \%$; type of support - material, financial: $I=70 \%$; amount of support: $I=30 \%$; how support is provided: $\mathrm{I}=35 \%$ ).

Overall, the Delphi panellists rated 63 concepts of high importance (of which 50 had a lower quartile of 8 or more), 13 of moderate importance and 12 of low importance for inclusion in a minimum set of concepts for RCT protocols (Tables 2 and 3). Most items had narrow IQRs, suggesting agreement between panel members. However, some items had IQRs that spanned from recommendations to exclude the item (five or less) to recommendations to include the item (eight or greater), such as Reporting of early stopping, Ancillary and substudies, trial Feasibility, Signatures and plans to monitor the health of pregnant women and their children (Pregnancy). These items were very often associated with comments stating that the concept is important but is either too specific for recommending in a minimum set for all trials or could be encompassed within another existing item.

\section{Summary of text responses}

Many general and item-specific comments were received during the three survey rounds and were retained for discussion by the SPIRIT group at subsequent face-toface consensus meetings; examples are highlighted here.

In general, many respondents stated that, although there were many items, most were important and hence rated highly. While some stated that there must be a 'balance between guiding researchers and being too prescriptive, others stated that a comprehensive list is more useful in light of the evidence for poor reporting in 


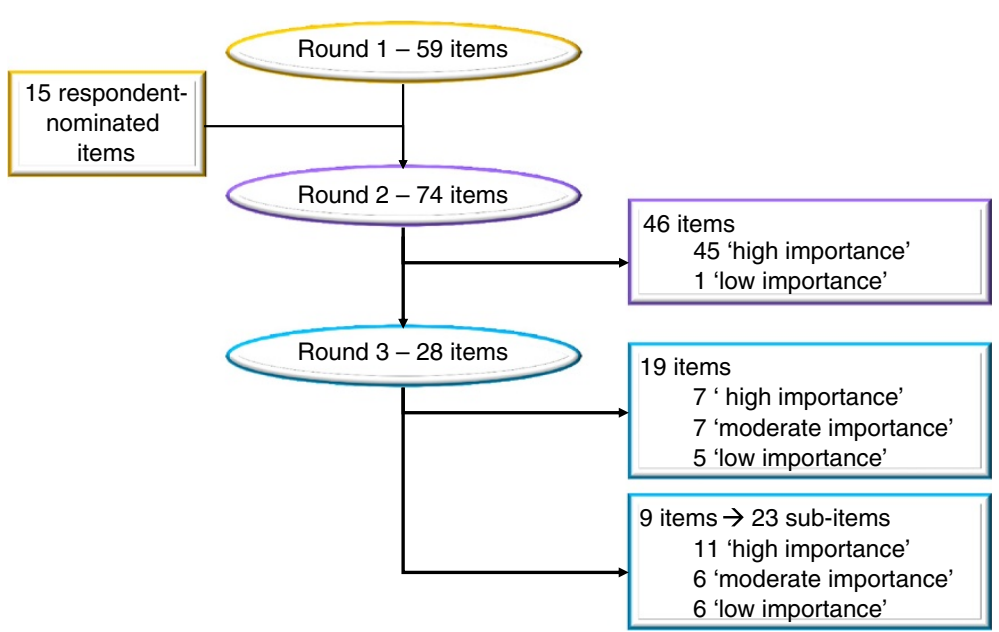

Figure 3 Flow of items through the Delphi survey.

protocols and due to the 'serious business' of clinical trials that 'deserve(s) a detailed reporting at any stage'. A few respondents were concerned, however, about the possible increased burden on trialists. Some suggested that some concepts may be addressed in associated documents (for example contracts, statistical and Data and Safety Monitoring Board (DSMB) charters, laboratory manuals) - with reference to such documents in the protocol - or through other sources (for example websites). Finally, some panellists suggested excluding items requiring repeated protocol amendments (for example Personnel, REC/IRB approval) to avoid jeopardizing trial progress with required official amendments and resubmissions.

Other general comments related to ambiguity of the term 'protocol', the desired scope of study designs that the checklist should address, and the potential need to define intended users of the protocol or checklist. Some noted that, while all items were potentially important elements, the importance of some may be relative to the target end user.

Item-specific comments consisted mostly of explanations to substantiate chosen ratings, suggested revisions, notes of potential overlap between and opportunities for merging items (for example Background, Rationale and Preliminary data; Risks, Harms and Adverse event reporting), and requests for clarification where items contained more than one concept or were vague. All comments were circulated to panellists in each round and delineations provided, where appropriate, in the final survey round.

\section{Subgroup analyses}

Subgroup analyses showed few differences between respondents by profession or level of self-perceived expertise (not shown). As examples, REB/IRB members and journals editors were more likely than other groups to support some concepts including a lay summary, a list of abbreviations, and justifications for study locations or eligibility criteria. There were no cases of bimodal results; rather, any differences were in the strength of support with overlapping IQRs. In some cases, the subgroup results enabled examination of the potential validity of additional comments. For example, while some panellists suggested that the items Logistics and Feasibility (which received low support overall) would be important to funding agencies but not to other end users, we found no difference between the opinions of our expert funding agency representatives and other groups for these items. This enabled greater insight and confidence for generating recommendations from the results.

\section{Discussion}

This Delphi survey produced rich information for further development of the SPIRIT Initiative, which aims to develop a guideline for clinical trial protocol content. Recent studies suggest that PubMed indexes over 6,000 RCTs annually [24] and this number has likely increased over time [25]. This finding does not account for trials indexed in other databases (between $20 \%$ and $70 \%$ of trials depending on the discipline [26]) and the minimum of $40 \%$ of trials not reaching full publication [27]. Given that all clinical trials should have a protocol, this Delphi and the SPIRIT Initiative have broad applicability.

Our panellists rated many concepts as highly important for inclusion in RCT protocols, most of which had a strong majority favouring inclusion, indicating consensus within the panel (for example narrow IQRs). The importance of some of these concepts, such as allocation concealment, outcomes (including delineation of primary outcomes), roles of sponsors, and conflicts of interest, are substantiated by strong empirical evidence 
Table 2 Consensus - concepts of 'high importance' for minimum protocol content following two or three survey rounds

General information

\begin{tabular}{llr}
\hline Title & Descriptive title identifying study design & $10(9,10)$ \\
\hline Trial identifier & Unique number/name and registration information & $10(9,10)$ \\
\hline Protocol version & Version or amendment number and date & $10(8,10)$ \\
\hline Protocol summary $\mathbf{A} \neq$ & Short summary of proposed research & I=94; E=5; U=1 \\
\hline Names and addresses & Names/addresses of primary investigators and sponsor & $10(8,10)$ \\
\hline Table of contents & List of contents and page numbers & $8(5,9)$ \\
\hline Introduction & & $10(9.5,10)$ \\
\hline Rationale & Outline topic and provide justification for study & $10(9,10)$ \\
\hline Background of the study & Summary of all previous studies (that is, a SR or reference) & $9(8,10)$ \\
\hline Preliminary data & Describe preliminary studies (for example by investigators) & $10(10,10)$ \\
\hline Objectives & Specific objectives and hypotheses for the study & I=87; E=11; U=2 \\
\hline Study location(s) A $\neq$ & Description of intended sites(s) &
\end{tabular}

Participants

Population

Eligibility criteria $A \neq$

Sample size

Recruitment

Design

Type of study

Study timeline $\mathbf{A} \neq$

Sequence generation

Allocation concealment

Random implementation

Blinding

Interventions

Interventions A $\neq$

Interventions $\mathrm{B} \neq$

Schedule of interventions

Concomitant interventions

Risks/Harms

Data collection / management

Outcomes

Data collection

Biological specimens $\S$

Validation of instruments $\S$

Follow-up

Data management

Quality control

Compliance

Statistical methods

Statistical methods

Withdrawals A $\neq$
Target and study population and source of the latter

$10(9,10)$ Description of inclusion and exclusion criteria (participants)

Estimated number; calculations and assumptions

$\mathrm{I}=99 ; \mathrm{E}=1 ; \mathrm{U}=0$

Process of recruitment (for example advertisements)

$10(10,10)$

Process of recruitment (for example advertisements) and enrolment

$9(8,10)$

Description of type/design and trial framework (for example superiority)

$10(10,10)$

Diagram of participants' procedures and visits through trial stages

$\mathrm{I}=84 ; \mathrm{E}=10 ; \mathrm{U}=6$

Method used to generate random sequence; details of any restriction

$10(9,10)$

Method used to implement random sequence and whether concealed

$10(10,10)$

Who will generate sequence, enrol participants and assign to groups

$10(8,10)$

Who (for example participants/investigators/outcome assessors)

$10(10,10)$

Precise details; how they will be administered (for example dosage, form)

$\mathrm{I}=99 ; \mathrm{E}=1 ; \mathrm{U}=0$

Justification of control

$\mathrm{I}=87 ; \mathrm{E}=8 ; \mathrm{U}=5$

Number and duration of treatment periods including run-in, washout $10(10,10)$

List of relevant treatments permitted or not before or during trial $10(9,10)$

Known or potential risks for each study intervention

$10(10,10)$

Describe and define primary and secondary outcomes

$10(10,10)$

Methods, instruments and timing of data collection and recording

$10(9,10)$

Laboratory evaluation, specimen collection, storage and shipping

$8(6,9)$

Reliability/validity of instruments or plans to establish validation

$8(6,9)$

Plans including description and schedule of visits and logistics

$10(9,10)$

Plans for data entry, editing, coding and storage

Methods for quality of outcome assessment and data records

$9(8,10)$

Procedures and measures to monitor participant compliance

$9(8,10)$

Methods for primary/secondary outcomes and additional analyses

$10(10,10)$

Criteria to withdraw or exclude participants from the intervention 
Table 2 Consensus - concepts of 'high importance' for minimum protocol content following two or three survey rounds (Continued)

\begin{tabular}{|c|c|c|}
\hline Withdrawals B $\neq$ & Data to be collected from, and follow-up of, withdrawn participants & $\mathrm{I}=85 ; \mathrm{E}=5 ; \mathrm{U}=10$ \\
\hline Missing data & Methods to account for missing or erroneous data & $9(8,10)$ \\
\hline Interim trial monitoring & Process and timing of any planned interim analyses & $10(9,10)$ \\
\hline Stopping guidelines $\mathbf{A} \neq$ & Predefined statistical stopping boundaries & $I=92 ; E=6 ; U=2$ \\
\hline Stopping guidelines $\mathbf{B} \neq$ & Non-statistical criteria for the early trial termination & $\mathrm{I}=76 ; \mathrm{E}=12 ; \mathrm{U}=12$ \\
\hline \multicolumn{3}{|l|}{ Safety and monitoring } \\
\hline Safety evaluations & Plans for monitoring safety including methods and timing. & $10(9,10)$ \\
\hline DSMB & If relevant, composition and role of DSMB & $9(9,10)$ \\
\hline Adverse event reporting & Methods of recording/reporting events; methods to deal with them & $10(9,10)$ \\
\hline Emergency code-breaking & Establishment/storage of code; when and by whom it can be broken & $10(8,10)$ \\
\hline Trial monitoring $\S$ & Plans and frequency including if independent & $8(6,9)$ \\
\hline \multicolumn{3}{|l|}{ Trial organization/administration } \\
\hline Monetary/material support $\mathbf{A} \neq$ & Source(s) of financial and material support & $I=94 ; E=5 ; U=1$ \\
\hline Data ownership§ & Who has ownership; contractual limits for principal investigators & $8(7,10)$ \\
\hline \multicolumn{3}{|l|}{ Ethical considerations } \\
\hline Potential benefits and risks & Potential benefits and risks to participants and society & $10(9,10)$ \\
\hline Agreement and consent & Method and person responsible; materials for potential participants & $10(9,10)$ \\
\hline Surrogate consent/assent & Method of obtaining surrogate consent or assent & $10(9,10)$ \\
\hline Confidentiality/Anonymity & Provisions for protecting personal data and privacy of participants & $10(9,10)$ \\
\hline Ethics approval & Whether it has been obtained and name of committees & $10(8,10)$ \\
\hline Role of sponsor & Role of sponsor in design, data collection, analysis, dissemination & $10(8,10)$ \\
\hline Conflict of interest & Financial or other real or perceived conflicts of interest & $10(8,10)$ \\
\hline Post-trial care $\S$ & Post-trial follow-up, access to treatment, duration; who is responsible & $8(6,9)$ \\
\hline \multicolumn{3}{|l|}{ Reporting and dissemination } \\
\hline Protocol amendments & Methods of communicating to investigators/IRBs and documenting & $9(7,10)$ \\
\hline Dissemination & How results will be disseminated to participants, practitioners, public & $8(7,10)$ \\
\hline Publication policy & Who has right to publish; restrictions; authorship guidelines & $9(7,10)$ \\
\hline Reporting of early stopping $\S$ & Dissemination of results if trial is stopped early (for any reason) & $8(5,10)$ \\
\hline \multicolumn{3}{|l|}{ Other } \\
\hline Limitations & Limitations of proposed study, including risk of bias & $8(6,10)$ \\
\hline References & List of references cited in protocol & $10(9,10)$ \\
\hline Data collection forms $\S$ & Summary table of all forms to be collected at each time point & $8(6,9)$ \\
\hline
\end{tabular}

associating them with risk of bias in trials [2,8,28-34]. Other concepts are supported by more pragmatic, regulatory or ethical rationale. Importantly, many of these concepts are often not described in protocols of RCTs $[1,3,9,10,35]$. This may be, in part, because most existing protocol content guidelines do not recommend such concepts [19]. The reasons for the variation between existing guidelines and our results are unclear as most guidelines do not report their methods of development.

Our results also indicate where panellists favoured excluding concepts and where a clear consensus was not attained. For the former, such as Budget and Logistics, the lack of support does not suggest that such items should not be included in protocols; only that they may be context-specific (for example not necessary for journal publication of protocols) and thus are not appropriate in a minimum set of requirements. Examples of the latter include items where wide IQRs remained. We believe that a systematic review of the methodological literature is important to complement the Delphi results and to guide and substantiate final recommendations.

Beyond the utility of the Delphi results for trialists, REC/IRBs representatives, funding agencies and the SPIRIT group, this research may be relevant to those developing reporting guidelines and our experience has already helped shape the methodology of other ongoing 
Table 3 Concepts of 'moderate' or 'low' importance for minimum protocol content following two or three survey rounds

\begin{tabular}{|c|c|c|}
\hline \multirow[t]{3}{*}{ Section and topic } & \multirow[t]{3}{*}{ Brief description* } & \multirow{3}{*}{$\begin{array}{c}\text { Results } \\
\text { Median (IQR) } \\
\text { or } \%+\end{array}$} \\
\hline & & \\
\hline & & \\
\hline \multicolumn{3}{|l|}{ Rated 'moderate' importance } \\
\hline Protocol summary $B \neq$ & Use of lay/non-technical language & $I=63 ; E=27 ; U=10$ \\
\hline List of abbreviations $\neq$ & List and descriptors of abbreviations used in protocol & $\mathrm{I}=74 ; \mathrm{E}=19 ; \mathrm{U}=8$ \\
\hline Eligibility criteria B & Justification of exclusion of subgroups & $I=66 ; E=28 ; U=6$ \\
\hline Monetary/materials support $\mathrm{B} \neq$ & List the type(s) of support provided & $I=70 ; E=21 ; U=10$ \\
\hline Feasibility§ & Acceptability for personnel/participants; capacity for recruitment & $6(3,8)$ \\
\hline Co-enrolment in studies $\S$ & Regulations pertaining to co-enrolment in other research studies & $7(5,8)$ \\
\hline Investigational product(s)§ & Formulation, packaging, labeling and supply; accountability & $7(5,9)$ \\
\hline Pregnancy§ & Monitoring of health of woman and child (short and long term) & $7(4,10)$ \\
\hline Ancillary and substudies $\S$ & Foreseen future uses of data or biological materials; consent & $7(5,9)$ \\
\hline Post-trial data/materials storage $\S$ & Data/materials storage: location(s), duration, responsibility & $7(4,8)$ \\
\hline Appendix materials $A \neq$ & Samples of the standardized case-report forms & $I=65 ; E=23 ; U=12$ \\
\hline Appendix materials $\mathrm{B} \neq$ & Other data collection forms (for example questionnaires) & $I=70 ; E=21 ; U=10$ \\
\hline Appendix materials $C \neq$ & Consent/assent forms & $I=72 ; E=23 ; U=5$ \\
\hline \multicolumn{3}{|l|}{ Rated 'low importance' } \\
\hline General approach $\neq$ & Outline the general approach to address the research question & $\mathrm{I}=52 ; \mathrm{E}=42 ; \mathrm{U}=6$ \\
\hline Study locations B $\neq$ & Briefly justify sites(s) where research is to be conducted & $I=46 ; E=46 ; U=8$ \\
\hline Study locations $\mathrm{C} \neq$ & Relevant demographic/epidemiological information of study region & $I=46 ; E=47 ; U=8$ \\
\hline Study timeline $B \neq$ & Schematic of the study stages' expected completion dates & $I=58 ; E=30 ; U=12$ \\
\hline Withdrawals $\mathrm{C} \neq$ & In a multicentre study, when a centre may be discontinued & $I=55 ; E=30 ; U=16$ \\
\hline Monetary/materials support C & The amount of support provided & $I=30 ; E=57 ; U=13$ \\
\hline Monetary/materials support $\mathrm{D} \neq$ & How support is provided (for example research account, honorarium) & $I=35 ; E=53 ; U=12$ \\
\hline Personnel $\neq$ & Names, affiliations, contact details of key trial personnel & $I=40 ; E=51 ; U=9$ \\
\hline Logistics $\neq$ & Availability of resources incl. administration, equipment, facilities & $I=27 ; E=64 ; U=10$ \\
\hline Budget & Budget for personnel, equipment, facilities and supplies & $5(2,6)$ \\
\hline Signatures§ & Signatures including principle investigators or chief medical officer & $5(2,8)$ \\
\hline Insurance§ & Plans including coverage to provide treatment and compensation & $5(2,7)$ \\
\hline
\end{tabular}

initiatives. Selecting potential panellists should be given adequate time and attention to ensure they meet the criteria suggested by previous guidance [21] as this is pivotal to both the internal and external validity (generalizability) of the Delphi results. Future endeavours should also consider empirically supported strategies to help increase response rates [36-42] including those used in the current study: survey prenotification/invitation to participate, personalized invitations and surveys, notification of and adherence to expected timelines, clear outline of expectations including time-commitments, written commitment by panellists to participate (reply by email), follow-up reminders to non-respondents, provision of previous rounds' responses and assurance of confidentiality. We also pilot tested each round, collected panellists' comments and employed a flexible survey design. Using an Internet-based tool may substantially increase Delphi efficiency and is recommended for future work.

Despite the many benefits of the Delphi consensus technique, the results are only as valid as the opinions of the experts constituting the panel. Even if consensus is attained, validating whether this consensus represents the 'truth' is not possible, and we recognize that expert opinion remains among the lowest levels of empirical evidence [43]. To safeguard the validity of our results, we carefully selected a panel representing key stakeholders. Structured, predefined methods were employed to minimize biased response collation. Importantly, our panellists were experienced and committed to completing the process, increasing internal validity of the results.

We chose the Delphi consensus method [21] for this work for several reasons: the research problem was felt 
to benefit from expert opinion on a collective basis; a larger and more diverse group could be consulted than could effectively meet face-to-face due to expense, size and the logistics of group interaction; and the preservation of participant anonymity allowed for open discussion. This method also shares the advantages of other integrative methods of knowledge translation [44] ideally resulting in a guideline that, beyond being founded on transparent and systematic methods, is externally valid and ultimately meets the needs of end users. We recommend this technique to others embarking on similar initiatives.

\section{Conclusion}

This Delphi consensus has provided a large volume of rich information to guide the development of the SPIRIT checklist, an evidence-based guideline for the content of trial protocols. By applying a formal consensus method and engaging experts from diverse areas, the results of which will be complemented by empirical evidence from the methodological literature, the aim is to collate guidance on important concepts to address in protocols. The SPIRIT Initiative ultimately aspires to help increase transparency and completeness of information in trial protocols, ideally helping to improve the reliability and validity of the medical literature guiding healthcare decisions.

\section{Abbreviations}

CONSORT: Consolidated Standards of Reporting Trials; IQR: interquartile range; RCT: randomized controlled trial; REC/IRB: research ethics committee/ institutional review board; SPIRIT: Standard Protocol Items: Recommendations for Interventional Trials.

\section{Competing interests}

The authors have declared that no competing interests exist. All authors are members of the SPIRIT Initiative Steering Group.

\section{Authors' contributions}

JMT, AWC and DM conceived the study and prepared the initial list of survey items. JMT designed and administered the survey, and collected and analyzed data. JMT wrote the first draft of the manuscript with input from all authors. All authors read and approved the final manuscript.

\section{Financial disclosure}

No direct funding was received for this study. The authors were personally salaried by their institutions during the period of writing (though no specific salary was set aside or given for the writing of this paper). Dr. Moher is supported, in part, by a University (of Ottawa) Research Chair. No funding bodies had any role in the study design, data collection, analysis, decision to publish or preparation of the manuscript.

\section{Acknowledgements}

We thank the Delphi panelists for their participation and for their dedication to seeing this process succeed. Their substantive feedback and support was very much appreciated given the significant request for their time.

\section{Author details}

'Ottawa Methods Centre, Clinical Epidemiology Program, Ottawa Hospital Research Institute, 501 Smyth Road, Ottawa, ON K1H 8L6, Canada. ${ }^{2}$ Department of Epidemiology and Community Medicine, Faculty of Medicine, University of Ottawa, 451 Smyth Road, Ottawa, ON K1H 8M5, Canada. 'Women's College Research Institute at Women's College Hospital, University of Toronto, 790 Bay Street, Toronto, ON M5G 1N8, Canada.
Received: 31 March 2012 Accepted: 7 September 2012

Published: 24 September 2012

\section{References}

1. Chan AW, Hróbjartsson A, Haahr MT, Gøtzsche PC, Altman DG: Empirical evidence for selective reporting of outcomes in randomized trials: comparison of protocols to published articles. JAMA 2004, 291:2457-2465.

2. Dwan K, Altman DG, Arnaiz JA, Bloom J, Chan AW, Cronin E, Decullier E, Easterbrook PJ, von Elm E, Gamble C, Ghersi D, loannidis JP, Simes J, Williamson PR: Systematic review of the empirical evidence of study publication bias and outcome reporting bias. PLOS One 2008, 3:3081.

3. Chan AW, Hróbjartsson A, Jørgensen KJ, Gøtzsche PC, Altman DG: Discrepancies in sample size calculations and data analyses reported in randomised trials: comparison of publications with protocols. BMJ 2008, 337:a2299.

4. Gluud LL: Bias in clinical intervention research. Am J Epidemio/ 2006, 163:493-501.

5. Bassler D, Ferreira Gl, Briel M, Cook DJ, Devereaux PJ, Heels AD, Kirpalani H, Meade MO, Montori VM, Rozenberg A, Schunemann HJ, Guyatt GH: Systematic reviewers neglect bias that results from trials stopped early for benefit. J Clin Epidemiol 2007, 60:869-873.

6. Chan AW, Krleža-Jeric K, Schmid I, Altman DG: Outcome reporting bias in randomized trials funded by the Canadian Institutes of Health Research. CMAJ 2004, 171:735-740.

7. Chan AW, Altman DG: Identifying outcome reporting bias in randomised trials on PubMed: review of publications and survey of authors. BMJ 2005, 330:753-759.

8. Lexchin J, Bero LA, Djulbegovic B, Clark O: Pharmaceutical industry sponsorship and research outcome and quality: systematic review. BMJ 2003, 326:1167-1170.

9. Pildal J, Chan AW, Hróbjartsson A, Forfang E, Altman DG, Gøtzsche PC: Comparison of descriptions of allocation concealment in trial protocols and the published reports: cohort study. BMJ 2005, 330:1049.

10. Gøtzsche P, Hrøbjartsson A, Johansen H, Haahr M, Altman D, Chan A: Ghost authorship in industry-initiated randomised trials. PLOS Med 2007, 4:e19. doi:10.1371/journal.pmed.0040019.

11. Plint AC, Moher D, Morrison A, Schulz K, Altman DG, Hill C, Gaboury I: Does the CONSORT checklist improve the quality of reports of randomised controlled trials? A systematic review. Med J Aust 2006, 185:263-267.

12. Smidt N, Rutjes AW, van der Windt DA, Ostelo RW, Bossuyt PM, Reitsma JB, Bouter LM, de Vet HC: The quality of diagnostic accuracy studies since the STARD statement: has it improved? Neurology 2006, 67:792-797.

13. Schulz KF, Altman DG, Moher D, CONSORT Group: CONSORT 2010 statement: updated guidelines for reporting parallel group randomised trials. PLOS Med 2010, 7:e1000251

14. Campbell MK, Elbourne DR, Altman DG, CONSORT group: CONSORT statement: extension to cluster randomised trials. BMJ 2004, 328:702-708.

15. Piaggio G, Elbourne DR, Altman DG, Pocock SJ, Evans SJW: Reporting of noninferiority and equivalence randomized trials: An extension of the CONSORT statement. JAMA 2006, 295:1152-1160.

16. Gagnier JJ, Boon H, Rochon P, Moher D, Barnes J, Bombardier C: Reporting randomized, controlled trials of herbal interventions: an elaborated CONSORT statement. Ann Intern Med 2006, 144:364-367.

17. Bossuyt PM, Reitsma JB, Bruns DE, Gatsonis CA, Glasziou PP, Irwig LM, Moher D, Rennie D, de Vet HC, Lijmer JG, Standards for Reporting of Diagnostic Accuracy Group: The STARD statement for reporting studies of diagnostic accuracy: explanation and elaboration. The Standards for Reporting of Diagnostic Accuracy Group. Croat Med J 2003, 44:639-650.

18. von Elm E, Altman DG, Egger M, Pocock SJ, Gøtzsche PC, Vandenbroucke JP: STROBE Initiative: The Strengthening the Reporting of Observational Studies in Epidemiology (STROBE) statement: guidelines for reporting observational studies. Lancet 2007, 370:1453-1457.

19. Tetzlaff JM, Chan A-W, Kitchen J, Sampson M, Tricco AC, Moher D Guidelines for randomized controlled trial protocol content: a systematic review. Syst Rev 2012, 1:43.

20. Moher D, Schulz KF, Simera I, Altman DG: Guidance for developers of health research reporting guidelines. PLoS Med 2009, 7:e1000217.

21. Adler M, Ziglio E: Gazing into the oracle: the Delphi method and its application to social policy and public health. Bristol, PA: Jessica Kingsley Publishers; 1996. 
22. Delbecq AL, Van de Ven AH, Gustafson DH: Group techniques for program planning: A guide to nominal group and Delphi processes. Glenview, IL: Scott, Foresman, and Company; 1975.

23. Institute for Scientific Information (ISI): Web of Knowledge [v 3.0]. ISI Highlycited.com [http://isiwebofknowledge.com/].

24. Chan AW, Altman DG: Epidemiology and reporting of randomised trials published in PubMed journals. Lancet 2005, 365:1159-1162.

25. Hopewell S, Dutton S, Yu L-M, Chan A-W, Altman DG: The quality of reports of randomised trials in 2000 and 2006: comparative study of articles indexed in PubMed. BMJ 2010, 340:723.

26. Dickersin K, Scherer R, Lefebvre C: Identifying relevant studies for systematic reviews. BMJ 1994, 309:1286-1291.

27. Scherer RW, Langenberg P, von Elm E: Full publication of results initially presented in abstracts. Cochrane Database Syst Rev 2007, 2:MR000005.

28. Pildal J, Hróbjartsson A, Jørgensen KJ, Hilden J, Altman DG, Gøtzsche PC: Impact of allocation concealment on conclusions drawn from metaanalyses of randomized trials. Int J Epidemiol 2007, 36:847-857.

29. Wood L, Egger M, Gluud LL, Schulz KF, Jüni P, Altman DG, Gluud C, Martin RM, Wood AJ, Sterne JA: Empirical evidence of bias in treatment effect estimates in controlled trials with different interventions and outcomes: meta-epidemiological study. BMJ 2008, 336:601-605.

30. Kunz R, Vist G, Oxman AD, Kunz R, Vist G, Oxman AD: Randomisation to protect against selection bias in healthcare trials. Cochrane Database Syst Rev 2007, 2:MR000012.

31. Bekelman JE, Li Y, Gross CP: Scope and impact of financial conflicts of interest in biomedical research: a systematic review. JAMA 2003, 289:454-465.

32. Kjaergard LL, Als-Nielsen B: Association between competing interests and authors' conclusions: epidemiological study of randomised clinical trials published in the BMJ. BMJ 2002, 325:249-253.

33. Bhandari M, Busse JW, Jackowski D, Montori VM, Schunemann H, Sprague S, Mears D, Schemitsch EH, Heels-Ansdell D, Devereaux PJ: Association between industry funding and statistically significant pro-industry findings in medical and surgical randomized trials. CMAJ 2004, 170:477-480.

34. Golder S, Loke YK: Is there evidence for biased reporting of published adverse effects data in pharmaceutical industry-funded studies? $\mathrm{Br} J \mathrm{Clin}$ Pharmacol 2008, 66:767-773.

35. Gøtzsche PC, Hróbjartsson A, Johansen HK, Haahr MT, Altman DG, Chan A-W: Ghost authorship in industry-initiated randomised trials. PLOS Med 2007, 4:0047-0052.

36. Edwards PJ, Roberts I, Clarke MJ, DiGuiseppi C, Wentz R, Kwan I, Cooper R, Felix LM, Pratap S: Methods to increase response to postal and electronic questionnaires. Cochrane Database Syst Rev 2009, 3:MR000008.

37. Dillman DA: Mail and internet surveys: The Tailored Design Method. New York: John Wiley; 1999.

38. Linstone HA, Turoff M: The Delphi Method: techniques and applications [book on the internet]. Linstone and Murray Turoff: Harold A; 2002.

39. Keeney S, Hasson F, McKenna H: Consulting the oracle: ten lessons from using the Delphi technique in nursing research. J Adv Nurs 2006, 53:205-212.

40. Okoli C, Pawlowski SD: The Delphi method as a research tool: an example, design considerations and applications. Inf Manage 2004, 42:15-29.

41. Rattray J, Jones MC: Essential elements of questionnaire design and development. J Clin Nurs 2005, 16:234-243.

42. Skulmoski GJ, Hartman FT, Krahn J: The Delphi method for graduate research. J Inf Technol Educ 2007, 6:1-21.

43. Evans D: Hierarchy of evidence: a framework for ranking evidence evaluating healthcare interventions. J Clin Nurs 2003, 12:77-84.

44. Canadian Institutes of Health Research: A guide to researcher and knowledge-user collaboration in health research. http://www.learning.cihr-irsc. gc.ca/mod/resource/view.php?id=157.

\section{doi:10.1186/1745-6215-13-176}

Cite this article as: Tetzlaff et al:: Developing a guideline for clinical trial protocol content: Delphi consensus survey. Trials 2012 13:176.

\section{Submit your next manuscript to BioMed Central and take full advantage of:}

- Convenient online submission

- Thorough peer review

- No space constraints or color figure charges

- Immediate publication on acceptance

- Inclusion in PubMed, CAS, Scopus and Google Scholar

- Research which is freely available for redistribution

Submit your manuscript at www.biomedcentral.com/submit 